\title{
Factors Influencing Professional Commitment of Public Secondary School Teachers in Trans-Nzoia West Sub-County, Kenya
}

\author{
${ }^{1}$ Nehemiah Kimutai Bett, ${ }^{2}$ Prof. Vencie B. Allida, PhD and ${ }^{3}$ Prof. Elizabeth Mendoza-Role, PhD \\ ${ }^{1}$ School of Education, University of Eastern Africa, Baraton, Kenya \\ ${ }^{2}$ Graduate Education and Leadership, Northern Caribbean University, Jamaica \\ ${ }^{3}$ Data Analyst and Research Consultant, Riverside, California, USA \\ "Corresponding author: vencie.allida@ncu.edu.jm
}

\begin{abstract}
This study sought to established factors influencing the professional commitment of public secondary school teachers in Trans-Nzoia West sub-county, Kenya. It adopted a descriptive correlational research design. Stratified random sampling was used to obtain categories of schools that best represent the entire population being studied. Cluster sampling technique was employed where all the 109 teachers from 10 randomly selected county schools, 58 teachers from the extra-county school and 67 teachers from the national school participated in the study. A total of 192 questionnaires were returned, giving a response rate of $82 \%$. Data were analyzed using descriptive statistics, Pearson product-moment correlation coefficient and multiple regression analysis. It was found that there is a significant direct relationship between teachers' professional commitment and their attitudes towards the teaching profession, beliefs about student learning, value systems and their evaluation of the school culture. These variables account for $83.6 \%$ of the variance in the professional commitment. It is therefore recommended that the schools should continue to find ways to enhance teachers' attitudes towards the teaching profession, beliefs about students' learning and value systems and the school culture in order to boost the teachers' professional commitment.
\end{abstract}

Key words: Professional commitment, attitudes, teaching profession, teachers' beliefs, value system, school culture

\section{Introduction}

Teaching is classified as a profession and a social service for national development and not simply an occupation aimed at making money for a livelihood. This calls upon teachers to be permanently committed to their work. Therefore, checking the commitment of a teacher is reasonable and timely to make education more desirable (Swarnalatha, 2016). Professional commitment means the feeling of dedication among the individuals of a group towards their profession (Shukla, 2014). Commitment involves two essential components namely-pride in one's being in the teaching profession and a strong desire for professional development. In fact after joining the profession, teachers should fully understand that as long as they are there, they have to develop pride, knowing that this is a noble profession charged with great responsibilities as the society hands over its children to this system for their wholesome education (Kaur \& Kaur, 2014).

Globally, governments, voluntary agencies, nongovernmental organizations and individuals commit significant resources towards building and developing teacher's professionalism. The need for improving teachers' commitment has been considered paramount since almost half of the new teachers left the profession in the first five years in Pakistan (Ahmed \& Iqbal, 2017).

Issues of teacher professional commitment are evident in literature emerging from the USA, UK and 
Australia (Swarnalatha, 2016; Kaur \& Kaur, 2014). Recent education reforms and the associated changes in working conditions and professional expectations have meant that issues of teacher professional commitment are being contested at both the level of policy and of practice (Buettner, Jeon, Hur, \& Garcia, 2016).

Indeed, current debates in the public and scholarly arena indicate that there are competing views about the nature of teacher professionalism (Buettner et al., 2016). Furthermore, in some instances, debates still circulate about whether or not teaching is a profession. Teachers' professionalism has come to be a site of struggle between various interest groups concerned with the broader enterprise of education. Some would say that it is in the best interests of governments for teaching to be seen as a profession as it gives greater opportunity for regulative control of the profession. Others would suggest that given the specialized knowledge base of teachers, the increased demand for professional standards and the great demands for teachers to see themselves as knowledge workers, then teaching has earned the status of being a profession in a more orthodox sense (Sorensen \& McKim, 2014).

In India, Basu (2016) found out that teaching is a highly noble profession and teachers are always a boon to the society. The ultimate process of education could be simplified as a meaningful interaction between the teacher and the taught. The teacher thus plays a direct and crucial role in molding students towards their education. Since a teacher is a role model for the students, job satisfaction and professional commitment of teachers become very vital in the fields of education.

Today there seems to be a dearth of deeply committed teachers who are completely devoted to their profession and at the same time satisfied with their profession. Lack of job satisfaction and professional commitment of teachers can often lead to stress, burnout, migration from the profession, less enthusiasm for the work and in general less motivation to perform well in teaching (Basu, 2016). Dissatisfied and less committed teachers cannot exert their whole hearted effort towards molding the future national citizens of a country. In a developing country like India, teachers with growing class size, work overload and job insecurity, professional commitment and job satisfaction are in danger of going to drop. This in turn could have serious ramifications for the entire nation's educational aspirations (Bashir, 2017).

A study conducted by Olurotimi, Asad and Abdulrauf (2015) in Nigeria, explains that teacher commitment is closely connected to teachers' work performance and their ability to innovate and to integrate new ideas into their own practice, absenteeism, staff turnover as well as having an important influence on students' achievement and attitudes toward school.

Teachers' commitment to their profession has been found to predict school effectiveness. A positive relationship is found between the organizational commitment and regular attendance, and an inverse relationship has been found between organizational commitment and turnover intention. Employees who are highly committed to both the profession and the organization were found to perform better than the less committed ones, a behavior which results in the improved overall effectiveness of the organization (Bogler \& Somech, 2004).

A study done by Wandia (2015) in Kenya on the influence of Teachers' Service Commission human resource management practices on teachers commitment in public secondary schools, shows that teachers' evaluation has substantially improved instruction or expanded student learning, thus improving teaching commitment. The study concludes that majority of the teachers believes if they work hard, they would be promoted to a higher rank. Teachers who have high career aspirations view their jobs as preparation for higher jobs.

The Teachers Service Commission is one of State's parastatals under the supervision of the Ministry of Education in Kenya. It is charged with the management and administration of teachers at the secondary school level in the state. Always, personnel management becomes its foremost responsibility. TSC personnel functions include appointment, posting, transfer, promotion, dismissal and enforcing disciplinary control over secondary school teachers and other staff within the Commission. The functions also include compilation and maintenance of teachers' records including registration of teachers, salary administration and payment of allowances to teachers and officials in the Commission. This study aimed at investigating the factors influencing professional commitment of public secondary school teachers in Trans-Nzoia West Sub-County, Kenya. 


\section{Research Methodology}

This section presents the methodology used to conduct the study. It addresses such aspects like research design, population and sampling, instruments and data collection procedures, statistical treatment of data and ethical considerations.

\section{Research Design}

This study employed the descriptive-correlational research design to investigate the factors influencing professional commitment of teachers (Robins, 2015). The correlational procedure was used because it allows one to make inferences about relationships between two or more variables (Okonedo, Popoola, Emmanuel, \& Bamigboye, 2015).

\section{Population and Sampling}

The research was carried out in Trans-Nzoia West Sub County. The area had a total of thirty-two (32) registered public secondary schools, where national school is one (1), extra county is one (1) and the county schools are thirty (30). The study targeted all public secondary school teachers in the Trans-Nzoia West Sub-county. Teachers were chosen to participate since they are the stakeholders of the professional commitment practices in secondary schools. While there were 492 teachers in the subcounty based on the 2018 record in the office of the sub-county Director of Education, stratified random sampling was used to obtain categories of schools so as to determine a sample that best represents the entire population being studied (Palinkas et al., 2015). Thirty percent of the total number of county schools were involved in the study. The 10 county schools which participated in the study were selected using a simple random sampling technique. The extra county and national schools were also included in the sample. This gives a total of 12 sampled schools including 10 county schools, 1 extra-county school, and 1 national school.

All the 234 teachers in the 12 schools participated in the study (109 teachers from 10 county schools, 58 teachers from the extra-county school and 67 from the national school. The 213 teachers who were present during the time of the study participated and 192 questionnaires were returned giving a response rate of $82 \%$.

\section{Instruments and Data Collection Procedures}

The researchers used a self-report questionnaire (Fernandez-Ballesteros, 2004) to gather information related to the objectives of the study from the participants. The instruments solicited the demographic information from respondents and had sections that measured teachers' commitment to their profession, attitude toward the teaching profession, beliefs on student learning, value system and school culture. The researchers reported to the Principal in each of the 12 sampled schools, introduced themselves and sought for permission to collect the data. The researchers then distributed the questionnaires to teachers in their respective offices. They gave the teachers time to fill the questionnaires and collected them after two hours of distribution.

\section{Statistical Treatment of Data}

Analysis of data involved descriptive statistic aspects such as means and standard deviations. The relationship between the dependent and independent variables was determined using Pearson product-moment correlation coefficient. Multiple regression analysis was used to determine the predictors of teacher professional commitment.

\section{Ethical Considerations}

The researchers obtained the ethics clearance letter from the University of Eastern Africa, Baraton research ethics committee. A letter of introduction was obtained from the Director of Graduate Studies so as to acquire a research authorization letter and a permit from the National Council for Science and Technology in the Ministry of Education, Science and Technology. The researchers then requested for permission from the County Commissioner and County Director of Education, Trans-Nzoia West Sub County to collect data from the sampled secondary schools.

\section{Findings and Discussion}

This section presents findings of the study based on the objectives that guided the study. The findings are discussed in the light of the literature review the researchers went through.

Research objective 1: To find out teachers' professional commitment, attitude towards the teaching profession, beliefs on student learning, value system and evaluation of the school culture.

The respondents were asked to rate their level of agreement to each statement measuring the construct on a scale of 1 to 4 . The mean score of each statement was interpreted based on a scale as follows: $3.50-4.00=$ Agree (High/Positive/Excellent), 
2.50-3.49 =Tend to agree (Average/Tend to be positive/Good), 1.50-2.49 = Tend to disagree (Below average/Tend to be negative/Fair) and 1.00-1.49= Disagree (Low/Negative/Poor)

Table 1 presents the means and standard deviations of teachers' professional commitment, attitude towards the teaching profession, beliefs on student learning, value system, and evaluation of the school culture.

Table 1: Descriptive Statistics

\begin{tabular}{lll}
\hline Variable & Mean & SD \\
\hline $\begin{array}{l}\text { Teachers' Professional } \\
\text { Commitment }\end{array}$ & 3.67 & .263 \\
$\begin{array}{l}\text { Teachers' Attitudes towards } \\
\text { Teaching Profession }\end{array}$ & 3.46 & .369 \\
$\begin{array}{l}\text { Teachers' Beliefs about Student } \\
\text { Learning }\end{array}$ & 3.72 & .264 \\
$\begin{array}{l}\text { Teachers' Value Systems } \\
\text { School Culture }\end{array}$ & 3.76 & .310 \\
\hline
\end{tabular}

\section{Teachers' Professional Commitment}

The overall response of the teachers on their professional commitment yielded a mean of 3.67 indicating that teachers are highly committed professionally. The standard deviation was 0.263 , which is low, indicating that the teachers were consistent in their response on professional commitment. This implies that generally, teachers in Trans-Nzoia public secondary schools have a high professional commitment.

According to Maiyani (2017), since professional commitment requires personal commitment and willingness to take on assignments and to acquire needed knowledge, it is important for teachers to work with honesty and transparency. The findings of this study indicate that the teachers had personal commitment and were willingness to take on assignments, acquired needed knowledge and worked with honesty and transparency.

This implies that the teachers are abiding by the rules and regulations and are embracing the principles of the teaching profession as well as the requirements. Committed teachers are firmly devoted to their work and greatly inspire their students. This level of commitment is an implication that students are inspired. The strength of any profession depends upon the degree of commitment of its members. A teacher who is committed to teaching is also committed to the school by devoting personal time to be an active member of the community and school organization. The teachers volunteered their free time to be on committees and teach after-school programs. They used their free time to support the programs of the school the best they could and hence were dedicated and they devoted to their profession.

\section{Teachers' Attitudes towards the Teaching Profession}

The overall mean of teachers' attitude towards the teaching profession was 3.46 indicating that they tended to have a positive attitude towards the teaching profession, with a standard deviation of 0.369 , which is low, indicating that the teachers were consistent in their response, meaning that generally, the attitude towards the teaching profession is towards the positive side.

In a study done by Andronache, Bocoş, Bocoş and Macri (2014), the results obtained showed that there was a significant positive correlation between the cognitive and the affective dimensions of teacher's attitude towards the teaching profession. Positive attitude towards the teaching profession implies that the teachers are ready to develop a conductive learner friendly environment in the classroom, which has a positive impact on learning.

A positive attitude towards the teaching profession can bring the desired quality in the education sector by developing a sense of duty, professional competence and by giving them an insight of the student's needs and problems. Thus, for the professional growth of the teachers and improvement in education, the attitudes held by them are very important. How a teacher performs his/her duty is dependent to a great extent, on his/her attitude. Whereas a positive attitude makes the work not only easier but also more satisfying and professionally rewarding, a negative attitude makes the teaching task harder, tedious and unpleasant. In addition, a teacher's attitude influences the behavior of her/his students. Thus, effective and productive learning on the part of students can be achieved only by teachers with positive attitude, which is the case in schools under investigation.

\section{Teachers' Beliefs about Students' Learning}

The overall response of teachers on their beliefs about students' learning yielded a mean of 3.72 indicating that teachers had a positive belief about students' learning. The average response yielded a 
standard deviation of 0.264 , which is low, indicating that the teachers had consistency in their response on beliefs about student learning. Teachers' beliefs play a significant role in shaping their instructional behaviors, and thus what students learn. As per the results of this study, teachers had a positive belief on what students learn. This was a positive representation of their subjective knowledge rather than objective knowledge on several criteria. The findings of this study on teachers' beliefs are in line with those of Diamond (2018) who established similar results and contended that teacher beliefs are related to effective learning through some events or sequence of events, mediated by the teacher, that happen in the classroom.

Teachers' beliefs appear to reflect their longstanding attitudes and their experiences in education rather than research-based knowledge about learning and motivation. Teachers' beliefs play a significant role in shaping their instructional behaviors, and thus what students learn. Positive beliefs about students' learning imply that teachers are working in conditions that support their beliefs and hence they appear consistent in their profession.

\section{Teachers' Value System}

The overall response of teachers on their value system yielded a mean of 3.76 indicating that teachers had a positive value system. The average response yielded a standard deviation of 0.310 , which is low, indicating that the teachers were consistent in their self-rating about their value systems. The more preferred instrumental values in the questionnaire by teachers are identified to be wisdom, honesty, capability and helpfulness. These value systems should be part of the curriculum so that they can be embraced as suggested by the study of Dasari (2017).

Teacher value system is a powerful influence on curriculum and instruction decisions. The positive value system implies that the teachers have a mastery of the content being taught, which makes them better teachers. This suggests that teachers are also involved in planning and preparation through conducting research and hence boost student performance and achievement. With the mastery of the content, teachers earn the respect of their administrators as administrators are able to know which teachers are putting in the necessary time to be an effective teacher and which teachers are not. Teachers investing extra time in their classroom will not go unnoticed by those around them. They will have a natural respect when they see how hard they work.

\section{Teachers' Evaluation of School Culture}

The mean evaluation of teachers on school culture is 3.98, indicating that teachers evaluated their school culture as excellent. The average evaluation yielded a standard deviation of 0.083 , which is low, indicating that the teachers are consistent in their evaluation on school culture, giving strength to the excellence of the culture of the public secondary schools under investigation.

As discussed by Ayık and Atas (2014) in their study, culture is believed to be an important factor that influences various aspects of human life, such as behavior, thinking, perceptions and attitudes which are core for teacher commitment. An excellent school culture implies that teachers and other staff members work together and share beliefs, values and assumptions. The positive school climate and school culture promotes students' ability to learn and a key element of school success. It is also an implication that there are many overlapping and cohesive interactions among all members of the school. A positive culture arises from messages that promote traits like collaboration, honesty and hard work among the teachers and students.

Research objective 2: To determine if there is a significant relationship between teachers' professional commitment and the following variables: attitudes towards the teaching profession, beliefs about student learning, value systems, and school culture.

To establish the relationship, Pearson productmoment correlation coefficient was used. Correlation coefficients range from -1 to +1 . Negative value of correlation coefficient indicates an inverse relationship while positive value indicates a direct relationship. Whereas a weak relationship is denoted by coefficient value of less than 0.3 , coefficient values ranging between 0.3 to 0.8 show a moderate relationship and correlation coefficients greater than or equal to 0.8 indicates a strong relationship.

As indicated in table 2, teachers' attitudes towards the teaching profession, beliefs about student learning, value systems and school culture have a 
positive correlation with the professional commitment (Pearson correlation coefficients of $0.144,0.633,0.858,0.308$, respectively). Teacher's attitude had a weak relationship with professional commitment while school culture and teachers' beliefs about students' learning had a moderate relationship with professional commitment. On the other hand, teachers' value system had a strong relationship with the professional commitment. The results of this study implies that teachers who have positive attitude towards the teaching profession, positive beliefs about students' learning, positive value systems and are serving in an institution with excellent school culture, tend to be more committed in the teaching profession.

Table 2: Correlation Coefficients

\begin{tabular}{lcc}
\hline \multicolumn{1}{c}{ Variables } & Correlations & Teachers' Professional Commitment \\
\hline Teachers' Attitudes towards Teaching & Pearson Correlation & $.144^{*}$ \\
Profession & Sig. (2-tailed) & .046 \\
& $\mathrm{~N}$ & 192 \\
Teachers' Beliefs about Student Learning & Pearson Correlation & $.633^{* *}$ \\
& Sig. (2-tailed) & .000 \\
Teachers' Value Systems & $\mathrm{N}$ & 192 \\
& Pearson Correlation & $.858^{* *}$ \\
& Sig. (2-tailed) & .000 \\
School Culture & $\mathrm{N}$ & 192 \\
& Pearson Correlation & $.308^{* *}$ \\
& Sig. (2-tailed) & .000 \\
& $\mathrm{~N}$ & 192
\end{tabular}

*. Correlation is significant at the 0.05 level (2-tailed).

**. Correlation is significant at the 0.01 level (2-tailed).

Karadag, Baloglu and Cakir (2011) analyzed direct and indirect relations between school culture and the professional commitment of primary school teachers in Turkey. The findings indicated that although there was a positive correlation between school culture and professional commitment, the direct effect of school culture on professional commitment was not meaningful. This was contrary to findings of this study as the correlation between school culture and professional commitment was significant. School cultures are influential. They shape and re-shape what people do, think and feel. Teachers are shaped by school cultures that they themselves might possibly have created. The results of this study are similar to the findings of Makau (2014) from her research that generally, organizational culture has an influence of teachers' job commitment.

As mentioned by Debdas and Santosh (2016), teacher's attitude towards the teaching profession is a factor influencing the professional commitment of public secondary school teachers. The results of this study are also supported by Malik and Rani (2013) who reported that there exists a significant positive correlation between attitude towards teaching and professional commitment.
While it is true that there are teachers whose attitudes are positive towards the profession, for most students, the reality of the school classroom consists of lessons where teaching is transmitted by their teachers, at best. The effective attitudes and actions employed by the teachers ultimately make a positive difference on the lives of the students, and this belief serves as the central focus of the profession. Attitude means the teacher's prevailing tendency to respond favorably or unfavorably to students.

As cited in Ige (2014), "teachers are the main determinants of the quality of education that if the teachers are ill motivated, apathetic, uncommitted, uninspired, lazy, dishonest, undisciplined and anti-social" (p. 28), then the profession and eventually, the whole nation is doomed. This assertion is supported by the findings of this study, showing that teachers who have positive value system are more committed to their profession. The roles of teachers in the education system goes beyond transmitting knowledge through the use of pedagogical skills but more of such things as values, value system and character of the teachers which exhibits interpersonal relationships between the teacher and the learners, hence determining the commitment of the teacher. 
Research objective 3: To identify the best predictors of teachers' professional commitment.

To find out the predictors of teachers' professional commitment, stepwise multiple regression analysis was used. This analysis provides the percentage of the variance in professional commitment accounted for by each independent variable. It also shows whether the regression model fits the data. It provides the coefficients that can be used to formulate the regression equation. The results of the analysis are presented in table 3 . The model summary provides the $R, R^{2}$, adjusted $R^{2}$, and the standard error of the estimate which represents the average distance that the observed values are fall from the regression line. The R-square value is the proportion of variation in the professional commitment accounted for by independent variables which entered the regression.
The regression analysis indicates that teachers' value systems, school culture, teachers' beliefs about students' learning and teachers' attitudes towards the teaching profession are significant predictors of teachers' professional commitment with a multiple correlation coefficient of .916. The percentage of the variance in the professional commitment accounted for by teachers' value systems is $73.5 \%$, by school culture is $5.1 \%$, by beliefs about student learning is $2.3 \%$, and by attitudes towards the teaching profession is $2.7 \%$ with a total of $83.6 \%$ strength of prediction. The ANOVA table tested whether the overall regression model is a good fit for the data. The table shows that the independent variables statistically significantly predict the dependent variable, $p<.000$ hence the regression model is a good fit of the data.

Model Summary

\begin{tabular}{|c|c|c|c|c|}
\hline Model & $\mathrm{R}$ & R Square & Adjusted R Square & $\begin{array}{c}\text { Std. Error of the } \\
\text { Estimate }\end{array}$ \\
\hline 1 & $.858^{\mathrm{a}}$ & .736 & .735 & .13568 \\
\hline 2 & $.888^{b}$ & .788 & .786 & .12183 \\
\hline 3 & $.901^{\mathrm{c}}$ & .812 & .809 & .11520 \\
\hline 4 & $.916^{d}$ & .840 & .836 & .10663 \\
\hline
\end{tabular}

a. Predictors: (Constant), Teachers' Value Systems

b. Predictors: (Constant), Teachers' Value Systems, School Culture

c. Predictors: (Constant), Teachers' Value Systems, School Culture, Teachers'

Beliefs about Student Learning

d. Predictors: (Constant), Teachers' Value Systems, School Culture, Teachers'

Beliefs about Student Learning, Teachers' Attitudes towards Teaching Profession

ANOVA $^{\mathrm{a}}$

\begin{tabular}{lrrrrr}
\hline Model & Sum of Squares & Df & Mean Square & \multicolumn{1}{c}{ F } & \multicolumn{1}{c}{ Sig. } \\
\hline Regression & 11.131 & 4 & 2.783 & 244.766 & $.000^{\mathrm{e}}$ \\
Residual & 2.126 & 187 & .011 & & \\
Total & 13.257 & 191 & & & \\
\hline
\end{tabular}

a. Dependent Variable: Teachers' Professional Commitment

Predictors: (Constant), Teachers' Value Systems, School Culture, Teachers' Beliefs about

Student Learning, Teachers' Attitudes towards Teaching Profession

Coefficients $^{\mathrm{a}}$

\begin{tabular}{|c|c|c|c|c|c|}
\hline \multirow[b]{3}{*}{ Model } & \multicolumn{5}{|c|}{ Standardized } \\
\hline & \multicolumn{2}{|c|}{ Unstandardized Coefficients } & \multirow{2}{*}{$\begin{array}{c}\text { Coefficients } \\
\text { Beta }\end{array}$} & \multirow[t]{2}{*}{$\mathrm{t}$} & \multirow[t]{2}{*}{ Sig. } \\
\hline & B & Std. Error & & & \\
\hline (Constant) & -3.854 & .468 & & -8.235 & .000 \\
\hline Teachers' Value Systems & .587 & .032 & .691 & 18.548 & .000 \\
\hline School Culture & 1.247 & .128 & .393 & 9.731 & .000 \\
\hline $\begin{array}{l}\text { Teachers' Beliefs about } \\
\text { Student Learning }\end{array}$ & .251 & .038 & .251 & 6.577 & .000 \\
\hline $\begin{array}{l}\text { Teachers' Attitudes } \\
\text { towards Teaching } \\
\text { Profession }\end{array}$ & -.167 & .029 & -.234 & -5.698 & .000 \\
\hline
\end{tabular}

a. Dependent Variable: Teachers' Professional Commitment

Predictors: (Constant), Teachers' Value Systems, School Culture, Teachers' Beliefs about Student Learning, Teachers' Attitudes towards Teaching Profession.

71 East African Journal of Education and Social Sciences (EAJESS) 1(2)65-73 
The predictive model is the linear regression equation as follows:

$Y=B_{1} X_{1}+B_{2} X_{2}+B_{3} X_{3}+B_{4} X_{4}+C$

Where $Y=$ Professional Commitment, $B_{i}=$ Beta coefficients, $X_{1}=$ Attitude, $X_{2}=$ Beliefs, $X_{3}=$ Values, $X_{4}=$ Culture and $C=$ Constant term. The linear regression equation to predict the teachers' professional commitment (Y) from the knowledge of value systems $\left(X_{1}\right)$, school culture $\left(\mathrm{X}_{2}\right)$, beliefs about student learning $\left(\mathrm{X}_{3}\right)$, and attitudes towards teaching profession $\left(\mathrm{X}_{4}\right)$ is as follows:

$Y=0.587 X_{1}+1.247 X_{2}+0.251 X_{3}-0.167 X_{4}-3.854$.

Atmosphere, culture, resources and social networks of a school are the major predictors of professional commitment in school. Similarly, Purba, Ambarita, and Siagian (2018) examined these variables as predictors of teacher commitment and the results showed that they were all significant predictors of increased professional commitment.

\section{Conclusion and Recommendations}

The study concludes that public secondary school teachers under investigation are highly committed to their profession. They have a moderate positive attitude towards the teaching profession and have a highly positive belief about students' learning and value system. The schools have an excellent school culture as evaluated by the teachers. Teachers have positive attitudes towards the teaching profession, positive beliefs about students' learning, positive value systems and are serving with an excellent school culture. They tend to be more committed to the teaching profession. School culture, value systems, beliefs about students' learning and attitude towards the teaching profession account for $83.6 \%$ of the variance in teachers' professional commitment.

It is recommended that the school management needs to support teachers with social services such as retreats, remedial, awards and the necessary teaching materials to boost the teachers' attitude towards the teaching profession and their value system. There is also a need to provide in-service training that will enlighten teachers on students' learning and establish a conducive school culture for teachers' professional commitment.

\section{Reference}

Ahmed, M., \& Iqbal, M. (2017). Developing a strategy for promoting government school teachers' commitment to profession. WALIA
Journal, 33(1), 31-35. Retrieved from http://waliaj.com/wpcontent/2017/Issue\%201,\%202017/6w.pdf

Andronache, D., Bocos, M., Bocos, V. \& Macri, C. (2014). Attitude towards teaching profession. Procedia - Social and Behavioral Sciences, 142, 628-632. https://cybe rleninka.org/article/n/504604/viewer

Ayik, A., \& Atas, O. (2014). An analysis of the relationship between high school teachers' organizational commitment levels and perceptions of school culture. Mevlana International Journal of Education, 4(3), 6982. http://mije.mevlana.edu.tr

Bashir, L. (2017). Job satisfaction of teachers in relation to professional commitment. The International Journal of Indian Psychology, 4(4). https://doi.org/10.25215/0404.007.

Basu, S. (2016). Professional commitment and job satisfaction among secondary school teachers. Educational Quest- An International Journal of Education and Applied Social Sciences, 7(3), 255-259.

Bogler, R., \& Somech, A. (2004). Influence of teacher empowerment on teachers organizational commitment, professional commitment and organizational citizenship behavior in schools. Teaching and Teacher Education, 20, 277-289.http://dx.doi.org/10. 1016/j.tate.2004.02.00 3

Buettner, C. K., Jeon, L., Hur, E., \& Garcia, R. E. (2016). Teachers' social-emotional capacity: Factors associated with teachers' responsiveness and professional commitment. Early Education and Development, 27(7), 1018-1039.

Dasari, R. P. (2017). Value system and value preferences of prospective teachers of secondary schools: An Indian survey. Universal Journal of Educational Research, 5(8), 1403-1409. https://doi.org/10.13189/ ujer .2017.050814.

Debdas, S., \& Santosh, K. B. (2016). Attitude of college teachers towards teaching profession. American Journal of Educational Research, 4(11), 834-839.

Diamond, J. M. (2018). Teachers' beliefs about students' transfer of learning. Journal of Mathematics Teacher Education, 22(5), 459487.Available online: https://doi.org/10.1007/s10857-018-9400$z$. 
Fernández-Ballesteros, R. (2004). Self-report questionnaires. In S. N. Haynes \& E. M. Heiby (Eds.), Comprehensive handbook of psychological assessment (Vol. 3). Behavioral assessment (pp. 194-221). Hoboken, NJ: John Wiley \& Sons.

Ige, A. M. (2014). Strategies for motivation of teachers for effectiveness amid universal basic education (UBE) programme implementation in Nigeria. European Journal of Academic Essays, 1(16), 28-35. http://oaji.net/articles/2016/36671481649670.pdf

Karadag, E., Baloglu, N., \& Cakir, A. (2011). A path analysis study of school culture and teachers' organizational commitment. Policy Futures in Education, 9(5), 573-584. https://doi.org/10.2304/pfie.2011.9.5.573

Kaur, K. \& Kaur, P. (2014). Professional commitment among secondary school teachers with respect to gender and locale. Electronic International Interdisciplinary Research Journal (EIIRJ), 3(6), 127-138. fromhttp://eiiri1.weebly.com/ploads/1/0 /8/0/10800505/khushwinder15@2014.p df.

Maiyani, N. J. (2017). Committed teacher: Teacher commitment and dedication to student learning. International Journal of Research and Analytical Reviews, 4(4), 109-110.

Retrieved from http://ijrar.com/.

Makau, B. K. (2014). Influence of organizational culture on teachers' job commitment in primary schools in Mwingi Central District, Kenya (Unpublished master's thesis). University of Nairobi, Kenya. Available online:https://pdfs.semanti cscholar.org/0d 1d/90878c8153518124a88dd0a053280f511 4f2.pdf.

Malik, U., \& Rani, M. (2013). Relationship between professional commitment and attitude towards teaching among secondary school teachers. Indian Journal of Applied Research, 3(10), 9-10. https://www.world widejournals.com/indian-journal-of-applied-
research-(IJAR)/fileview/October_2013

_1493101964_31.pdf

Okonedo, S., Popoola, S. O., Emmanuel, S. O., \& Bamigboye, O. B. (2015). Correlational analysis of demographic factors, selfconcept and research productivity of librarians in public universities in SouthWest, Nigeria. International Journal of Library Science, 4(3), 43-52.

Olurotimi, O. J., Asad, K. W., \& Abdulrauf, A. (2015). Motivational factors and teachers' commitment in public secondary schools in Mbale municipality. Journal of Education and Practice, 6(15), 117-122. Retrieved from www.iiste.org.

Palinkas, L. A., Horwitz, S. M., Green, C. A., Wisdom, J. P., Duan, N., \& Hoagwood, K. (2015). Purposeful sampling for qualitative data collection and analysis in mixed method implementation research. Administration and Policy in Mental Health and Mental Health Services Research, 42(5), 533-544.

Robins, G. (2015). Doing social network research: Network-based research design for social scientists. Los Angeles, CA: Sage Publications.

Shukla, S. (2014). Teaching competency, professional commitment and job satisfaction-a study of primary school teachers. Journal of Research \& Method in Education, 4(3), 44-64.

Sorensen, T. J., \& McKim, A. J. (2014). Perceived work-life balance ability, job satisfaction, and professional commitment among agriculture teachers. Journal of Agricultural Education, 55(4), 116-132.

Swarnalatha, S. (2016). Work commitment of secondary school teachers. The International Journal of Indian Psychology, 3(4). DOI: 10.25215/0304.163

Wandia, K. E. (2015). Influence of teachers' service commission human resource management practices on teachers commitment in public secondary schools in Tetu Sub County, Nyeri. University of Nairobi, Kenya. 